\title{
Biosurfactant: Production and Application
}

\section{Fakruddin Md*}

Industrial Microbiology Laboratory, Institute of Food Science and Technology (IFST), Bangladesh Council of Scientific and Industrial Research (BCSIR), Dhaka, Bangladesh

\begin{abstract}
Microbial surfactants (Biosurfactants) are amphiphilic compounds produced in living spaces or excreted extracellular hydrophobic and hydrophilic moieties that confer on the organism the ability to accumulate between fluid phases thus reducing surface and interfacial tension. Biosurfactants are produced by several microorganisms which include Acinetobacter sp., Bacillus sp, Candida antartica, Pseudomonas aeruginosa. The physiological role of biosurfactant production in microorganisms includes antimicrobial activity and the ability to make substrates readily available for uptake by the cells in adverse environmental conditions. Biosurfactant are classified based on their molecular weight and chemical composition. Some advantages of biosurfactants are biodegradability, low toxicity, better surface and interfacial activity while some of its limitations are inability to scale up the production process and patent rights. Factors influencing biosurfactants production are the nature of the carbon source, nitrogen source, the $\mathrm{C}: \mathrm{N}$ Ratio, temperature, aeration and $\mathrm{pH}$. Biosurfactants have several applications in agriculture, industry, medicine and the petroleum sectors.
\end{abstract}

Keywords: Biosurfactants; Applications; Factors; Production

\section{Introduction}

Biosurfactants are amphiphilic compounds produced in living surfaces, mostly on microbial cell surfaces or excreted extracellular hydrophobic and hydrophilic moieties that confer the ability to accumulate between fluid phases, thus reducing surface and interfacial tension at the surface and interface respectively [1]. They possess the characteristic property of reducing the surface and interfacial tension using the same mechanisms as chemicals surfactants [2].

Surfactants are the active ingredients found in soaps and detergents with the ability to concentrate at the air- water interface and are commonly used to separate oily materials from a particular media due to the fact that they are able to increase aqueous solubility of NonAqueous Phase Liquids (NAPLS) by reducing their surface/ interfacial tension at air-water and water-oil interfaces [3].

Biosurfactants are mainly classified according to their chemical structure and their microbial origin. The main classes of biosurfactants are glycolipids, phospholipids, polymeric biosurfactants and lipopeptides (surfactin). The best known glycolipids are rhamnolipids, sophorolipids and trehalolipids [3,4] Figure 1.

Surfactants are widely used for industrial, agricultural, food, cosmetics and pharmaceutical application however most of these compounds are synthesized chemically and potentially cause environmental and toxicology problem due to the recalcitrant and persistent nature of these substances [4]. With current advances in biotechnology, attention has been paid to the alternative environmental friendly process for production of different types of biosurfactants from microorganisms [5].

\section{Advantages of biosurfactants}

Biosurfactants have many advantages when compared to their chemically synthesized counterparts, some of these are:

Biodegradability: Biological surfactants are easily degraded by microorganism [6].

Low toxicity: Biosurfactant demonstrate higher toxicity than the chemical-derived surfactants. It was also reported that biosurfactants showed higher EC 50 (effective concentration to decrease $50 \%$ of test population) values than synthetic dispersants [7].

Availability of raw materials: Biosurfactants can be produced from very cheap raw materials which are available in large quantities. The carbon source may come from hydrocarbons, carbohydrates and /or lipids, which may be used separately or in combination with each other [8].

Physical factors: Many biosurfactants are not affected by environmental factors such as temperature, $\mathrm{pH}$ and ionic strength tolerances. Lichenysin produced by Bacillus licheniformis strain was not affected by temperature ranges of up to $50^{\circ} \mathrm{C}$, a $\mathrm{pH}$ range of 4-59.0, and $\mathrm{NaCl}$ concentration of $50 \mathrm{~g} / \mathrm{l}$ and $\mathrm{Ca}$ concentration of $25 \mathrm{~g} / \mathrm{l}$. [9].

Surface and interface activity: Mulligan [10] stated that a good surfactant can lower surface tension of water from 75 to $35 \mathrm{mN} / \mathrm{m}$ and the interfacial tension water/hexadecane from 40 to $1 \mathrm{mN} / \mathrm{M}$. Surfactin possess the ability to reduce the surface tension of water to $25 \mathrm{~m} \mathrm{~N} / \mathrm{M}$ and the interfacial tension of water/hexadecane to $<1 \mathrm{mN} / \mathrm{M}[9]$.

Other advantages: Kosaric [8] are biocompatibility and digestibility which allows their application in cosmetic, pharmaceuticals and as functional food additives.

\section{Physiological role of biosurfactant in microorganisms}

Biosurfactants are produced by a variety of a microorganism; they are secreted either extracellular or attached to parts of cells predominantly during growth on water immiscible substrates [7]. The main physiological role of biosurfactants is to permit microorganisms to grow on water-immiscible substrates by reducing the surface

*Corresponding author: Fakruddin Md, Scientific Officer, Industrial Microbiology Laboratory, Institute of Food Science and Technology (IFST), Bangladesh, E-mail: fakruddinmurad@gmail.com

Received May 15, 2012; Accepted June 13, 2012; Published June 15, 2012

Citation: Fakruddin Md (2012) Biosurfactant: Production and Application. J Pet Environ Biotechnol 3:124. doi:10.4172/2157-7463.1000124

Copyright: (c) 2012 Fakruddin Md, et al. This is an open-access article distributed under the terms of the Creative Commons Attribution License, which permits unrestricted use, distribution, and reproduction in any medium, provided the original author and source are credited. 


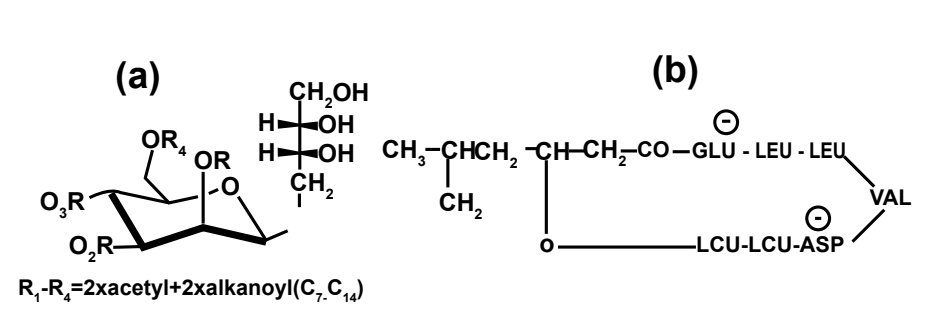

(d)

(e)
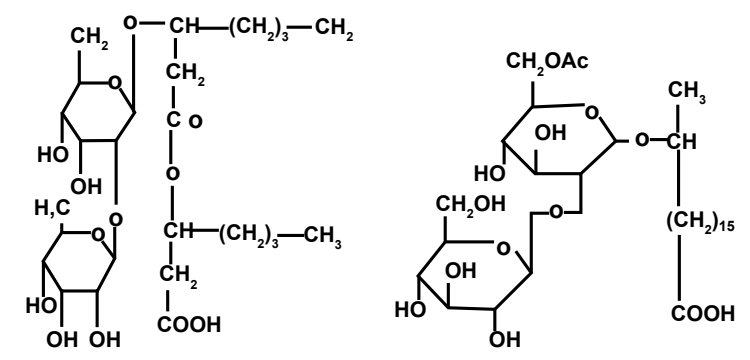
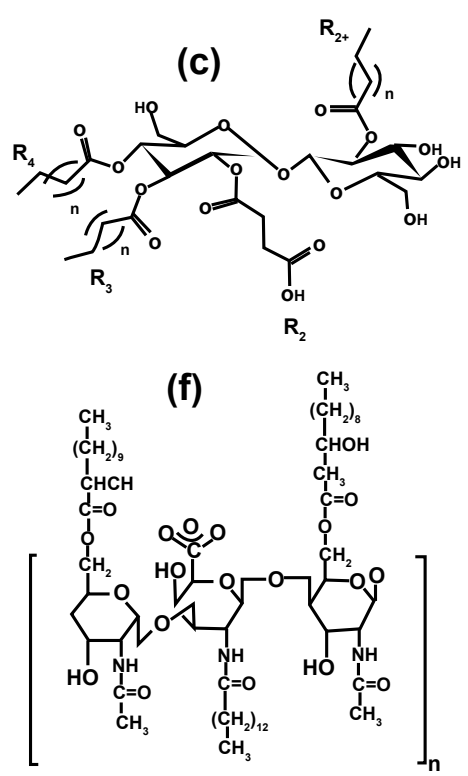

Figure 1: Chemical structures of some common biosurfactants (a) Mannosylerythritol lipid (b) Surfactin (c) trehalose lipid (d) Sophorolipid (e) Rhamnolipid (f) Emulsan.

tension at the phase boundary, thus making the substrate more readily available for uptake and metabolism, though the molecular mechanism related to the uptake of their substrates are still not clear and not fully understood [7]. Ron and Rosenberg [11] suggested that when the surface area becomes limiting, biomass increases arithmetically rather than exponentially, the evidence that emulsification is a natural process brought about by extra-cellular agents is indirect and there are certain conceptual difficulties in understanding how emulsification can provide an (evolutionary) advantage for the micro-organism producing the emulsifiers.

Another physiological role of biosurfactants is their antimicrobial activities towards various micro-organisms. As a rule, different surfactant inhibits different taxonomy. In addition biosurfactants have been shown to be involved in cell adherence which imparts greatest stability under hostile environmental conditions and virulence and in cell desorption when organisms need to find new habitats for survival [7].

\section{Factors affecting biosurfactant production}

The composition and emulsifying activity of the biosurfactant not only depends on the producer strain but also on the culture conditions, thus, the nature of the carbon source, the nitrogen source as well as the $\mathrm{C}: \mathrm{N}$ ratio, nutritional limitations, chemical and physical parameters such as temperature, aeration, divalent cations and $\mathrm{pH}$ influence not only the amount of biosurfactant produced but also the type of polymer produced [12].

Carbon sources: The quality and quantity of biosurfactant production are affected and influenced by the nature of the carbon substrate [13]. Diesel, crude oil, glucose, sucrose, glycerol have been reported to be a good source of carbon substrate for biosurfactant production [7].

Nitrogen sources: Nitrogen is important in the biosurfactant production medium because it is essential for microbial growth as protein and enzyme syntheses depend on it. Different nitrogen compounds have been used for the production of biosurfactants such as urea peptone, yeast extract, ammonium sulphate, ammonium nitrate, sodium nitrate, meat extract and malt extracts. Though yeast extract is the most used nitrogen source for biosurfactant production, its usage with respect to concentration is organism and culture medium dependent. Ammonium salts and urea are preferred nitrogen sources for biosurfactant production by Arthrobacter paraffineus whereas nitrate supports maximum surfactant production in P. aeruginosa [14].

Environmental factors: These are extremely important in the yield and characteristics of the biosurfactant produced. To obtain large quantities of biosurfactants, it is always necessary to optimize the bioprocess as the product may be affected by changes in temperature, $\mathrm{pH}$, aeration or agitation speed. Most biosurfactant productions are reported to be performed in a temperature range of 25-300C [7]. The effect of $\mathrm{pH}$ on biosurfactant produced was studied by Zinjarde and Pant [15] who reported that the best production occurred when the $\mathrm{pH}$ was 8.0 which is the natural $\mathrm{pH}$ of sea water.

Aeration and Agitation: Aeration and agitation are important factors that influence the production of biosurfactants as both facilitate the oxygen transfer from the gas phase to the aqueous phase. It may also be linked to the physiological function of microbial emulsifier, it has been suggested that the production of bioemulsifiers can enhance the solubilization of water insoluble substrates and consequently facilitate nutrient transport to microorganisms. Adamczak and Bednarski [14] observed that the best production value of the surfactant $(45.5 \mathrm{~g} / \mathrm{l})$ was obtained when the air flow rate was $1 \mathrm{vvm}$ and the dissolved oxygen concentration was maintained at $50 \%$ of saturation.

Salt concentration: Salt concentration of a particular medium also had a corresponding effect on the biosurfactant production as the cellular activities of microorganisms are affected by salt concentration. Nevertheless, contrary observations were noticed for some biosurfactant products which were not affected by concentrations up to $10 \%$ (weight/ volume) although slight reductions in the CMC were detected [7]. 


\section{Commercial Applications of Biosurfactants}

The worldwide production of surfactants amount increased to 17 million metric tones in 2000 (including soaps) expected future growth rates of $3-4 \%$ per year globally [13]. These chemically synthesized surfactants are mainly petroleum based and are usually non biodegradable thus remain toxic to the environment they find themselves. Also these compounds may bio-accumulate and their production processes and by-products can be environmentally hazardous, due to this increasing awareness on the need to protect the ecosystem, environmental scientist have been tightening environment regulations thus necessitating an increased interest in surfactants of microbial origin as possible alternatives to chemically synthesized ones [16]. Biosurfactants have several applications in agriculture, medicine, petroleum and industry.

\section{Application of Biosurfactants in Agriculture}

One way to enhance the solubility of bio-hazardous chemical compounds such as PAH is to apply surfactants as mobilizing agents. This increases the apparent solubility of Hydrophobic Organic Contaminants (HOC). Also surfactants are said to help microbes adsorb to soil particles occupied by pollutants, thus decreasing the diffusion path length between the site of absorption and site of biouptake by the microorganisms [4]. Also in agriculture, surfactants are used for hydrophilization of heavy soils to obtain good wettability and to achieve even distribution of fertilizer in the soil. They also prevent the caking of certain fertilizer during storage and promote spreading and penetration of the toxicants in pesticides [4].

The rhamnolipid biosurfactant, mostly produced by the genus Pseudomonas is known to possess potent antimicrobial activity. Further, no adverse effects on humans or the environments are anticipated from aggregate exposure to rhamnolipid biosurfactants. Fengycins are also reported to possess antifungal activity and therefore may be employed in biocontrol of plant diseases [17].

\section{Applications of biosurfactants in commercial Laundry detergents}

Almost all surfactants, an important component used in modern day commercial laundry detergents, are chemically synthesized and exert toxicity to fresh water living organisms. Growing public awareness about the environmental hazards and risks associated with chemical surfactants has stimulated the search for ecofriendly, natural substitutes of chemical surfactants in laundry detergents. Biosurfactants such as Cyclic Lipopeptide (CLP) are stable over a wide $\mathrm{pH}$ range (7.012.0) and heating them at high temperature does not result in any loss of their surface-active property [18]. They showed good emulsion formation capability with vegetable oils and demonstrated excellent compatibility and stability with commercial laundry detergents favoring their inclusion in laundry detergents formulation [19].

\section{Biosurfactants as Biopesticide}

Conventional arthropod control strategy involves applications of broad-spectrum chemicals and pesticides, which often produce undesirable effects. Further, emergence of pesticide resistant insect populations as well as rising prices of new chemical pesticides have stimulated the search for new eco-friendly vector control tools. Lipopeptide biosurfactants produced by several bacteria exhibit insecticidal activity against fruit fly Drosophila melanogaster and hence are promising to be used as biopesticide [10].

\section{Application of biosurfactants in medicine}

Mukherjee et al. [20] elucidated on the wide range of applications of biosurfactants in medicine they include:

Antimicrobial activity: The diverse structures of biosurfactants confer them the ability to display versatile performance. By its structure, biosurfactants exerts its toxicity on the cell membrane permeability bearing the similitude of a detergent like effect [21].

Gharaei-Fathabad [22] reported that several biosurfactants have strong antibacterial, antifungal and antivirus activity; these surfactants play the role of anti adhesive agents to pathogens making them useful for treating many diseases as well as its use as therapeutic and probiotic agent. A good example is the biosurfactant produced by marine $B$. circulans that had a potent antimicrobial activity against Gram positive and Gram negative pathogens and Semi pathogenic microbial strains including MDR strain.

Anti-cancer activity: Some microbial extracellular glycolipids induce cell differentiation instead of cell proliferation in the human promyelocytic leukemia cell line, also, exposure of PC 12 cells to MEL enhanced the activity of acetylcholine esterase and interrupted the cell cycle at the G1 phase with resulting overgrowth of neurites and partial cellular differentiation, this suggest that MEL induces neuronal differentiation in PC 12 cells and provides the ground work for the use of microbial extracellular glycolipids as novel reagents for the treatment of cancer cells [9].

Anti-adhesive agents: Biosurfactants have been found to inhibit the adhesion of pathogenic organisms to solid surfaces or to infection sites, Rodrigues et al. [23] demonstrated that pre-coating vinyl urethral catheter by running the surfactin solution through them before inoculation with media resulted in the decrease in the amount of -biofilm formed by Salmonella typhimurium, Salmonella enterica, E. coli and Proteus mirabilis. Muthusamy et al. [9] reported that pretreatment of silicone rubber with $S$. thermophilus surfactant inhibited $85 \%$ adhesion of C. albicans and surfactants from L. fermentum and $L$. acidophilus adsorbed on glass, reduced by $77 \%$ the number of adhering uropathogenic cells of Enterococcus faecalis.

Immunological adjuvants: Bacterial lipopeptides constitute potent non-toxic, nonpyrogenic immunological adjuvants when mixed with conventional antigens. An improvement of the humoral humane response was demonstrated when low molecular mass antigens Iturin $\mathrm{AL}$ and herbicolin A [22].

Antiviral activity: Antibiotic effects and inhibition of growth of human immunodeficiency virus in leucocytes by biosurfactants have been cited in literature [7, 9]. Furthermore, Muthusamy et al. [9] reported that due to the increased incidence of HIV in women, there arose the need for a female controlled, efficacious and safe vaginal topical microbicide. Sophorolipids surfactants from C. bombicola and its structural analogues such as the sophorolipid diacetate ethyl ester is the most potent spermicidal and virucidal agent, it was also reported that this substance has a virucidal activity similar to nonoxynol - 9 against the human semen.

Gene delivery: Gharaei-Fathabad [22] stated that the establishment of an efficient and safe method for introducing exogenous nucleotides into mammalian cells is critical for basic sciences and clinical applications.

Other: Other advantages and applications of bio-surfactant in 


\begin{tabular}{|c|c|c|c|}
\hline MEOR agents & Microbes & Product & Possible application \\
\hline & Bacillus sp. & \multirow{3}{*}{ Cells and EPS (mainly exopolysaccharides) } & \multirow{3}{*}{$\begin{array}{l}\text { Selective plugging of oil depleted zones and wettability angle } \\
\text { alteration }\end{array}$} \\
\hline & Leuconostoc & & \\
\hline & Xanthomonas & & \\
\hline \multirow[t]{5}{*}{ Surfactants } & Acinetobacter & Emulsan and alas an & \\
\hline & Bacillus sp. & Surfactin, rhamnolipid, lichenysin & \multirow{3}{*}{$\begin{array}{l}\text { Emulsification and deemulsification through reduction of } \\
\text { interfacial tension }\end{array}$} \\
\hline & Pseudomonas & Rhamnolipid, glycolipids & \\
\hline & Rhodococcus sp. & Viscosin and trehaloselipids & \\
\hline & Arthrobacter & & \multirow{7}{*}{ Injectivity profile and viscosity modification, selective plugging } \\
\hline \multirow[t]{6}{*}{ Biopolymers } & Xanthomonas sp. & Xanthan gum & \\
\hline & Aureobasidium sp. & Pullulan & \\
\hline & Bacillus sp. & Levan & \\
\hline & Alcaligenes sp. & Curdlan & \\
\hline & Leuconostoc sp. & Dextran & \\
\hline & Sclerotium sp. & Scleroglucan & \\
\hline \multirow[t]{3}{*}{ solvents } & Clostridium, & \multirow{3}{*}{ Acetone, butanol, propan-2-diol } & \multirow{3}{*}{$\begin{array}{l}\text { Rock dissolution for increasing permeability, oil viscosity } \\
\text { reduction }\end{array}$} \\
\hline & Zymomonas and & & \\
\hline & Klebsiella & & \\
\hline \multirow[t]{3}{*}{ Acids } & Clostridium & \multirow{3}{*}{ Propionic and butyric acids } & \multirow{3}{*}{ Permeability increase, emulsification } \\
\hline & Enterobacter & & \\
\hline & Mixed acidogens & & \\
\hline \multirow[t]{3}{*}{ Gases } & Clostridium & \multirow{3}{*}{ Methane and hydrogenc } & \multirow{3}{*}{$\begin{array}{l}\text { Increased pressure, oil swelling, reduction of interfacial section } \\
\text { and viscosity, increase permeability }\end{array}$} \\
\hline & Enterobacter & & \\
\hline & Methanobacterium & & \\
\hline
\end{tabular}

Table 1: Possible applications of biosurfactants produced by microorganisms in Microbial enhanced oil recovery (MEOR) [25].

medicine are the use of surfactants as agents for stimulating stem fibroblast metabolism, immunomodulatory action, however it has been reported in literature that the deficiency of pulmonary surfactant, a phospholipids protein complex is responsible for the failure of respiration in prematurely born infants however, isolation of genes for protein molecules of this surfactant and cloning in bacteria have made possible its fermentation production for medical application [9].

\section{Application of biosurfactant in food processing industry}

Biosurfactants have been used for various food processing application but they usually play a role as food formulation ingredient and anti-adhesive agents, as food formulation ingredient they promote the formation and stabilization of emulsion due to their ability to decrease the surface and interfacial tension. It is also used to control the agglomeration of fat globules, stabilize aerated systems, improve texture and shelf-life of starch-containing products, modify rheological properties of wheat dough and improve consistency and texture of fatbased products [9].

\section{Application of biosurfactant in cosmetic industry}

In the cosmetic industry, due to its emulsification, foaming, water binding capacity, spreading and wetting properties effect on viscosity and on product consistency, biosurfactant have been proposed to replace chemically synthesized surfactants. These surfactants are used as emulsifiers, foaming agents, solubilizers, wetting agents, cleansers, antimicrobial agents, mediators of enzyme action, in insect repellents, antacids, bath products, acne pads, anti dandruff products, contact lens solutions, baby products, mascara, lipsticks, toothpaste, dentine cleansers to mention but a few [22].

\section{Application of biosurfactant in petroleum}

Biosurfactant and bioemulsifiers are novel group of molecules and among the most powerful and versatile by-product that modern microbial technology can offer in fields such as bio-corrosion and biofouling degradation of hydrocarbons within oil reservoirs, enzymes and biocatalysts for petroleum up-grading [24]. Furthermore, biosurfactants play a major role in petroleum extraction, transportation, upgrading and refining and petrochemical manufacturing.

\section{Application of biosurfactant in microbial enhanced oil recovery}

Microbial enhanced oil recovery includes use of microorganisms and the exploitation of their metabolic processes to increase production of oil from marginally producing reservoirs. Microbial surfactants are widely used in oil recovery in recent times. The mechanism responsible for oil release is acidification of the solid phase. Certain microorganisms, such as Bacillus subtilis, Pseudomonas aeruginosa, Torulopsis bombicola have been reported to utilize crude oil \& hydrocarbons as sole carbon sources \& can be used for oil spill clean-ups [19]. Table 1 delineates possible applications of biosurfactants in microbial enhanced oil recovery and reduction of surface tension.

\section{Conclusion and Recommendations}

In spite of many laboratory based success in biosurfactants production and its immense commercial applications, the production of biosurfactant at a plant scale remains a challenging issue as the composition of final product is affected by the nutrient, micronutrient and environmental factors. Guideline and regulation should be formulated for use of biosurfactants in different sectors. It is expected that in future, super-active microbial strains will be developed using genetic engineering for production of biosurfactants at industrial level using renewable substrates as raw material.

\section{References}

1. Cunha CD, Do Rosario M, Rosado AS, Leite SGF (2004) Serratia sp SVGG 16 A promising bio-surfactant producer isolated from tropical soil during growth with ethanol-blended gasoline. Process Biochem 39: 2277-2282.

2. Singh A, Van Hanne JD, Ward OP (2007) Surfactants in microbiology and biotechnology: Part 2. Application aspects. Biotechnol Adv 25: 99-121. 
3. Yin $\mathrm{H}$, Qiang $\mathrm{Y}$, Jia $\mathrm{Y}, \mathrm{Ye} \mathrm{J}$, Peng $\mathrm{H}$, et al. (2009) Characteristics of biosurfactant produced by Pseudomonas aeruginosa $\mathrm{S} 6$ isolated from oil -containing wastewater. Process Biochem 44: 302-308.

4. Makkar RS, Rockne KJ (2003) Comparison of synthetic surfactants and biosurfactants in enhancing biodegradation of polycyclic aromatic hydrocarbon. Environ Toxicol Chem 22: 2280-2292

5. Lotfabad TB, Shourian M, Roostaazad R, Najafabadi AR, Adelzadeh MR, et al. (2009) An efficient biosurfactant-producing bacterium Pseudomonas aeruginosa MR01, isolated from oil excavation areas in south of Iran. Colloids Surf B Biointerfaces 69: 183-193.

6. Mohan PK, Nakhla G, Yanful EK (2006) Biokinetics of biodegradation of surfactants under aerobic, anoxic and anaerobic conditions. Water Res 40 533-540.

7. Desai JD, Banat IM (1997) Microbial production of surfactants and their commercial potential. Microbiol Mol Biol Rev 61: 47- 64.

8. Kosaric N (2001) Biosurfactants and their Applications for Soil Bioremediation Food Technol Biotechnol 39: 295-304.

9. Krishnaswamy M, Subbuchettiar G, Ravi TK, Panchaksharam S (2008) Biosurfactants properties, commercial production and application. Current Science 94: 736-747.

10. Mulligan CN (2005) Environmental applications for biosurfactants. Environ pollut 133: 183-198.

11. Ron EZ, Rosenberg E (2001) Natural roles of biosurfactants. Environ Microbio 3: 229-236.

12. Salihu A, Abdulkadir I, Almustapha MN (2009) An investigation for potential development of biosurfactants. Microbiol Mol Biol Rev 3: 111-117.

13. Rahman PKSM, Gakpe E (2008) Production, characterization and application of Biosurfactants-Review. Biotechnology 7: 360-370.

14. Adamczak M, Bednarski W (2000) Influence of medium composition and aeration on the synthesis of biosurfactants produced by Candida antartica.
Biotechnol Lett 22: 313-316.

15. Zinjarde SS, Pant A (2002) Emulsifier from a tropical marine yeast Yarrowia lipolytica NCIM 3589. J Basic Microbiol 42: 67-73.

16. Benincasa M (2007) Rhamnolipid produced from agroindustrial wastes enhances hydrocarbon biodegradation in contaminated soil. Curr Microbiol 54 445-449.

17. Kachholz T, Schlingmann M (1987) Possible food and agricultural application of microbial surfactants: an assessment. In: Kosaric N, Cairns WL, Grey NCC (eds.), Biosurfactant and Biotechnology, New York, Marcel Dekker Inc. 25 183-208.

18. Mukherjee AK (2007) Potential Application of Cyclic lipopeptide biosurfactants produced by Bacillus subtilis strains in laundry detergent formulations. Lett App Microbiol 45: 330-335.

19. Das K, Mukherjee AK (2007) Crude petroleum-oil biodegradation efficiency of Bacillus subtilis and Pseudomonas aeruginosa strains isolated from petroleum oil contaminated soil from North-East India. Bioresource Technol 98: 13391345.

20. Mukherjee S, Das P, Sen R (2006) Towards commercial production of microbial surfactants. Trends Biotechnol 24: 509-515

21. Zhao Z, Wang Q, Wang K, Brain K, Liu C, et al. (2010) Study of the antifungal activity of Bacillus vallismortis ZZ185 in vitro and identification of its antifungal components. Bioresour technol 101: 292-297.

22. Gharaei-Fathabad E (2011) Biosurfactants in pharmaceutical industry: A Min - Review. American Journal of Drug Discovering and Development 1: 58-69.

23. Rodrigues L, Banat IM, Teixeira J, Oliveira R (2006) Biosurfactant; potentia applications in medicine. J Antimicrob Chemother 57: 609-618.

24. Perfumo A, Rancich I, Banat IM (2010) Possibility and challenges for biosurfactant uses in petroleum industry. Adv Exp Med Biol 672: 135-145.

25. Sen R (2008) Biotechnology in petroleum recovery: The microbial EOR. Progress in Energy and Combustion Science 34: 714-724. 